\title{
Combined use of solid-state NMR spectroscopy and theoretical modelling as a method of structure determination.
}

\author{
Mihails Arhangelskis, ${ }^{\mathrm{a}}$ Robin Stein, ${ }^{\mathrm{a}}$ Andrew J. Morris, ${ }^{\mathrm{b}}$ Mark D. Eddleston, ${ }^{\mathrm{c}}$ Nadeesh \\ Madusanka, ${ }^{\mathrm{c}}$ William Jones ${ }^{\mathrm{c}}$ and Tomislav Friščić ${ }^{\mathrm{a}}$ \\ ${ }^{a}$ Department of Chemistry, McGill University, Montreal, Canada \\ ${ }^{\mathrm{b}}$ Theory of Condensed Matter Group, Cavendish Laboratory, University of Cambridge, \\ Cambridge, UK \\ ${ }^{\mathrm{c}}$ Department of Chemistry, University of Cambridge, Cambridge, UK
}

NMR crystallography is an area of materials research concerned with acquiring structural information by combining solid-state NMR spectroscopy with theoretical modelling of NMR parameters. The development of this research field has been facilitated by the development of highly accurate methods for calculating NMR parameters in periodic structures. In particular, calculations with the Gauge Including Projector Augmented Waves (GIPAW) ${ }^{1}$ method routinely show a $2 \mathrm{ppm}$ accuracy for ${ }^{13} \mathrm{C}$ spectra, ${ }^{2}$ making them invaluable in helping assign the spectra and distinguish polymorphic structures.

In this presentation an overview of NMR functionality in a plane-wave DFT code CASTEP $^{3}$ will be given, highlighting its use in NMR crystallography. We will present several studies where combined use of experimental NMR spectroscopy and modelling is used as an aid in structure determination of tautomers, spectra assignment, and improving the overall understanding of structural features responsible for spectroscopic variations. ${ }^{4-6}$

(1) Pickard, C. J.; Mauri, F. Phys. Rev. B 2001, 63, 245101.

(2) Salager, E.; Day, G. M.; Stein, R. S.; Pickard, C. J.; Elena, B.; Emsley, L. J. Am. Chem. Soc. 2010, 132, 2564.

(3) Segall, M. D.; Lindan, P. J. D.; Probert, M. J.; Pickard, C. J.; Hasnip, P. J.; Clark, S. J.; Payne, M. C. J. Phys. Condens. Matter 2002, 14, 2717.

(4) Arhangelskis, M.; Eddleston, M. D.; Reid, D. G.; Day, G. M.; Bučar, D.-K.; Morris, A. J.; Jones, W. Chem. Eur. J. 2016, 22, 10065.

(5) Madusanka, N.; Eddleston, M. D.; Arhangelskis, M.; Jones, W. Acta Crystallogr. B. Struct. Sci. Cryst. Eng. Mater. 2014, 70, 72.

(6) Hasa, D.; Miniussi, E.; Jones, W. Cryst. Growth Des. 2016, 16, 4582. 